\title{
Avaliação Qualitativa em Medicina: Experiência em Propedêutica Médica na UFBA, 2003
}

\author{
Qualitative Evaluation in Medicine: an \\ Experiment in Medical Propaedeutics at \\ UFBA, 2003
}

Dolores Araújo ${ }^{1}$ André Luiz Peixinho ${ }^{2}$

PALAVRAS-CHAVE

- Avaliação Educacional;

- Currículo;

- Empirismo;

- Educação Médica.

KEY-WORDS

- Educational Measurement;

- Curriculum;

- Empiricism;

- Education, Medical.

Recebido em: 13/04/2005

Reencaminhado em: 03/09/2005

Reencaminhado em: 18/04/2006

Aprovado em: 25/04/2006

\section{RESUMO}

No momento atual, reconhece-se a necessidade de a educação médica promover mudanças de modo a formar profissionais com um perfil mais humanizado. Para alcançar tal propósito, é essencial investir em transformações no campo da avaliação. O principal objetivo deste trabalho é descrever as diversas funções do diário de campo como instrumento de avaliação educacional. Trata-se de estudo de caso qualitativo, que envolve a leitura de diários de campo de alunos matriculados nos semestres 2003.1 e 2003.2, na disciplina Clínica Propedêutica Médica I, Faculdade de Medicina - UFBA. Utilizou-se a análise de conteúdo como técnica principal de interpretação dos dados coletados. Com base nos relatos dos estudantes sobre suas aulas práticas, obteve-se uma visão ampla acerca de suas experiências nos primeiros contatos com pacientes, seus julgamentos acerca das atividades e do desempenho do professor, assim como da evolução de seu aprendizado. O diário de campo 1) permite acompanhar as atividades práticas e a atuação didática dos professores; 2) fornece subsídios para a avaliação dos estudantes em termos afetivos; 3) serve como recurso para a reformulação da prática pedagógica a partir do feedback dos discentes; 4) funciona para o estudante como instrumento de auto-avaliação.

\begin{abstract}
Today one recognizes the need of promoting some changes in medical education aimed at graduating professionals with a more humanistic profile. To achieve this goal it seems essential to invest in new evaluation procedures. The main objective of this study consists in describing the use of daily records as an instrument of educational evaluation. The present paper is a qualitative case study involving the reading of the daily records produced by the students enroIled in the course on Propaedeutic Medicine I, of the Faculty of Medicine - UFBA during the year of 2003. The research relied mainly on techniques of interpretation of contents of the collected data. The analysis of reports on practical activities allowed for a broad understanding of the students' experiences in their first contact with patients, how they judge their daily activities and the performance of the teachers as well as their view of their own learning progress. The daily record: 1) allows for monitoring the practical classroom activities and the performance in terms of teaching methodology; 2) provides elements for the affective evaluation of the students; 3) serves as a resource for the reformulation of pedagogical practices based on the feedback from the students; 4) works as an instrument for self-evaluation for the students.
\end{abstract}




\section{INTRODUÇÃO}

No mundo atual, é necessário que a educação contribua para o desenvolvimento integral do indivíduo, possibilitando a este uma inserção harmoniosa no ambiente sociocultural. Sua concepção tem sido bastante ampliada nos últimos decênios, de modo que o relatório da Unesco ${ }^{1}$ acerca dos quatro pilares da educação destaca, entre outros aspectos, a importância de aprender a ser e a viver com os outros.

Em termos da educação médica, nas últimas décadas, vem se configurando a importância de formar um profissional com um perfil mais adequado às necessidades dos pacientes. A formação tradicional do médico segue um modelo biomédico, que reduz o ser humano a um organismo biológico². Entre as deficiências observadas, tem-se enfatizado a formação ética e humanística insatisfatória. Dessa forma, um dos desafios atuais da formação médica é recuperar essa dimensão humana, questão inserida no processo educacional.

Os princípios da Declaração de Edimburgo ${ }^{3}$, resultante da Conferência Mundial de Educação Médica em Edimburgo, na Escócia, em 1988, têm orientado os movimentos de transformação e inovação da educação médica em diversos países. No caso do Brasil, como assinala Briani ${ }^{4}$, as principais reformas curriculares se iniciaram a partir da realização dessa conferência, sendo por ela claramente influenciadas.

No Brasil, dois documentos têm influência marcante na delineação do novo paradigma: a Portaria no 126 do MEC (01/ 02/99) sobre o Exame Nacional do Curso de Medicina e as Diretrizes Curriculares Nacionais para os Cursos de Graduação em Medicina, instituídas em novembro de 2001. Essa portaria descreveu as especificações do "produto", ou seja, o perfil do graduando em Medicina, ao passo que as diretrizes funcionam como uma bússola direcionadora do processo ${ }^{5}$.

A análise dos três documentos citados permite destacar algumas idéias-chave relacionadas ao perfil desejado do estudante de Medicina. Uma adequada relação médico-paciente representa um aspecto essencial do aprendizado, e, para isso, são importantes a atitude empática frente ao doente, a observação de princípios éticos e a habilidade de se comunicar adequadamente. O paciente deve ser visto em sua totalidade, compreendendo-se outras dimensões que não aquelas meramente biológicas. Para treinar adequadamente o aluno em relação a essas competências, é preciso saber estimular atitudes e valores adequados ao perfil desejado.

Para o aprimoramento do processo de ensino-aprendizagem, em qualquer área do conhecimento, a avaliação representa um elemento de fundamental importância. O processo de avaliar, por outro lado, não pode ser dissociado dos objetivos educacionais, ou seja, dos tipos de mudança de comporta- mento que uma instituição educacional se esforça por estimular em seus alunos'.

Bloom ${ }^{7}$ classifica os objetivos educacionais em três domínios: cognitivo (conhecimentos e habilidades intelectuais), afetivo (interesses, atitudes e valores) e psicomotor (habilidades motoras ou manuais). A maioria das situações de aprendizado obtém resultados nos três domínios, de tal modo que a avaliação educacional necessita abranger os três aspectos. Assim, em termos de Medicina, um processo abrangente de avaliação deveria envolver aspectos cognitivos, habilidades e competências práticas, assim como atitudes e características pessoais dos alunos 8 .

No entanto, como assinala Melchior ${ }^{9}$, no ensino superior, em geral, a avaliação se restringe aos aspectos cognitivos e, em alguns casos, ao aspecto psicomotor. O curso médico, evidentemente, não constitui exceção. Entretanto, se é necessário desenvolver um profissional com um perfil mais humanizado, é preciso, entre outras medidas, criar meios de avaliar os estudantes de Medicina em termos afetivos. Isso se justifica pelo fato de a avaliação funcionar como um meio particularmente eficiente de moldar comportamentos e influenciar a aprendizagem ${ }^{6,10}$.

A avaliação não pode se restringir apenas ao desempenho do estudante, mas deve abranger também conteúdos programáticos do curso, atividades didáticas, desempenho dos professores, etc. A necessidade de avaliar de forma mais ampla a educação médica no Brasil fez surgir a Comissão Interinstitucional Nacional de Avaliação do Ensino Médico (Cinaem), que, desde 1991, vem se dedicando à avaliação de características de escolas médicas brasileiras e a propor novas formas de otimização do ensino na área.

Em seu sentido mais amplo, a avaliação funciona como um processo em que se coletam e utilizam informações que permitem a tomada de decisões sobre o programa educacional ${ }^{11}$. Para tais informações serem obtidas, a participação dos alunos se mostra de fundamental importância.

No entanto, Brown ${ }^{12}$ chama a atenção para a lacuna existente na literatura acerca da visão do estudante sobre o processo de aprendizado. Nas raras pesquisas que se centralizam na experiência do aluno, utilizam-se breves levantamentos ou questionários para colher as opiniões dos estudantes. O que se obtém dessa forma não parece refletir suas percepções enquanto engajados nas atividades didáticas. Também não se observa a mútua influência existente entre alunos e professores, nem o que pensam e pelo que se interessam enquanto estão sofrendo os efeitos dessa mútua influência ${ }^{12}$. No entanto, tem sido amplamente reconhecido que a relação professor-aluno tem um papel significativo no processo de aprendizagem ${ }^{13,14,15}$. 
O diário de campo é um instrumento no qual se anotam lugar, data e situação, fatos e acontecimentos observados, assim como comentários pessoais acerca dos mesmos. Tem sido recomendado como instrumento privilegiado de coleta de dados na pesquisa etnográfica ou na qualitativa, de forma geral, assim como na antropologia. No Brasil, tem havido um número crescente de livros e artigos de pesquisadores em educação sobre o assunto ${ }^{16}$.

Na disciplina Clínica Propedêutica Médica I, da Faculdade de Medicina da Universidade Federal da Bahia (UFBA), os diários de campo vêm sendo utilizados, desde 1996, como forma de relatos dos alunos sobre suas experiências em atividades práticas. Trata-se de uma rica fonte de dados sobre diversos aspectos da vivência dos estudantes, que também permite um acompanhamento detalhado do desempenho do professor e do desenvolvimento das atividades didáticas.

A possibilidade de alunos de Medicina escreverem sobre os pacientes em linguagem não técnica auxilia no desenvolvimento da chamada competência narrativa, definida como o conjunto de habilidades requeridas para reconhecer, absorver, interpretar e ser mobilizado pelas histórias que se ouve ou lê. $\mathrm{O}$ aprimoramento das habilidades narrativas pode auxiliar no desenvolvimento de uma série de capacidades de que atualmente se sente falta na Medicina, tais como sintonia com a individualidade do paciente, sensibilidade em relação às dimensões emocionais ou culturais do cuidar, compromisso ético com pacientes, etc ${ }^{17}$.

O presente trabalho visa evidenciar as diversas funções do diário de campo como instrumento de avaliação qualitativa na referida disciplina, assim como relatar experiências dos estudantes nos primeiros contatos com pacientes e trazer sua perspectiva acerca do processo de aprendizagem e da relação estabelecida com os professores. $\mathrm{O}$ material aqui apresentado constitui parte dos dados utilizados em dissertação de mestrado no Curso de Pós-Graduação em Medicina e Saúde, da Faculdade de Medicina da Bahia, Universidade Federal da Bahia.

\section{METODOLOGIA}

\section{Modo de construção da amostragem e critérios de inclusão dos sujeitos}

Foram utilizados como objeto de observação diários de campo escritos por alunos da disciplina Clínica Propedêutica Médica I, da Faculdade de Medicina da Bahia (UFBA). Essa disciplina é oferecida a alunos do quarto semestre e faz parte do currículo mínimo. Em cada semestre há em média 75 alunos, e se pede que todos escrevam diários de campo.
O período de leitura incluiu o primeiro e o segundo semestres de 2003. Como critério de exclusão, estabeleceu-se a retirada do estudo dos diários de campo dos alunos que não os entregaram em número suficiente para uma adequada avaliação. Como quantidade mínima aceitável, foram adotados diários de campo correspondentes a pelo menos $50 \%$ das aulas práticas realizadas no semestre. Dessa forma, foram incluídos, no total, diários de campo de 138 alunos, sendo 79 $(57,25 \%)$ do sexo masculino e $59(42,75 \%)$ do sexo feminino, excluindo-se da pesquisa 15 alunos, sendo 14 homens $(93,33 \%)$ e 1 mulher $(6,67 \%)$.

O projeto de pesquisa foi aprovado pelo Comitê de Ética em Pesquisa da Universidade Federal da Bahia.

\section{Método(s) científico(s) da pesquisa e técnicas para coleta de dados}

A pesquisa realizada adotou o desenho de estudo de caso, utilizando abordagem qualitativa. A seguir, serão tecidas algumas considerações acerca da escolha metodológica.

O termo pesquisa qualitativa se refere a qualquer tipo de investigação que gera dados não alcançados por meio de procedimentos estatísticos ou outros modos de quantificação ${ }^{18}$. Este tipo de pesquisa é utilizado para estudar organizações, grupos e indivíduos.

O presente trabalho, que envolve a leitura de diários de campo individuais de alunos de Medicina, requer uma abordagem que privilegie a compreensão de como eles reagem às experiências de aprendizado. O que é observado e descrito faz parte de um contexto particular, que envolve a disciplina Clínica Propedêutica Médica I, não havendo interferências intencionais sobre o que acontece aos estudantes. $\mathrm{O}$ foco principal da leitura dos diários de campo está no significado que os alunos dão às suas diferentes vivências ao longo do semestre. Por outro lado, com base nos dados coletados, chega-se a certas conclusões, de modo que se segue o processo mental da indução. Dessa forma, a investigação pretendida se enquadra nas características gerais da abordagem qualitativa ${ }^{19}$.

Nosso estudo aborda uma situação singular e claramente definida - experiências dos alunos de Clínica Propedêutica Médica I em suas aulas práticas -, mas os dados e conclusões obtidos são aplicáveis em contextos semelhantes. O interesse da pesquisa se concentra fundamentalmente em termos de como os alunos vivenciam as atividades práticas e como se consegue utilizar o diário de campo como instrumento de avaliação. Por tais motivos, essa investigação assume a forma de estudo de caso $20,21,22$, o qual, atualmente, vem sendo cada vez mais utilizado em educação ${ }^{23,24}$. 
No presente trabalho, a análise documental é utilizada como técnica principal de apreensão de dados. Para Lüdke e André20, ela representa um método valioso de abordagem de dados qualitativos. Utilizam a definição de Phillips ${ }^{20}$ para documentos: "quaisquer materiais escritos que possam ser usados como fontes de informação sobre o comportamento humano", e, entre estes, estão incluídos diários pessoais. Uma das situações básicas em que se considera adequado o uso da análise documental é quando existe o interesse em estudar o problema a partir da própria expressão dos indivíduos ${ }^{20}$. Por outro lado, como em geral se escreve um diário sob a influência imediata de uma experiência, ele pode se mostrar particularmente eficiente em captar o humor das pessoas e seus pensamentos mais íntimos ${ }^{19}$.

\section{Procedimentos utilizados na etapa de campo}

Ao se iniciar o semestre, os alunos recebem informações gerais sobre como devem elaborar seus diários de campo, que são apresentadas no manual da disciplina. As atividades práticas de Clínica Propedêutica Médica I se realizam em ambulatórios e/ou hospitais, com carga de quatro horas diárias, em duas ou três manhãs em cada semana. Os estudantes são divididos em turmas de, em média, seis alunos, cada uma delas conduzida pelo mesmo professor durante todo o semestre. As atividades práticas aqui referidas são o objeto dos relatos dos estudantes. Garante-se a eles o sigilo das informações dadas como forma de estimular a expressão livre de suas idéias e sentimentos. Os professores não têm acesso direto aos diários de campo em nenhum momento do curso, nem mesmo após a conclusão do semestre. Além disso, o docente responsável pela leitura dos mesmos não ensina em nenhuma das turmas práticas.

Os diários de campo são entregues pelos alunos a cada duas semanas. Dados relevantes obtidos a partir de sua leitura foram registrados pela pesquisadora em dois tipos de fichas de leitura. O primeiro deles envolve aspectos relacionados com o professor e as atividades de cada turma prática. Por outro lado, cada aluno dispõe de uma ficha individual de leitura, e nela se fazem transcrições literais de manifestações significativas dos estudantes, tendo-se o cuidado de contextualizá-las. Ao final do diário do aluno, se necessário, são feitos comentários, ou apenas se rubrica, assinalando, assim, a leitura do mesmo. Quando se recebe um novo lote de diários de campo, devolvem-se todos aqueles da quinzena anterior.

\section{Técnicas para análise dos dados coletados}

O material colhido a partir das anotações feitas nas fichas de leitura foi processado a partir do emprego da análise de conteúdo, definida como uma técnica de pesquisa que possibilita fazer inferências válidas e replicáveis dos dados para o seu contexto ${ }^{20}$. A análise de conteúdo trabalha com o conteúdo simbólico das mensagens, as quais podem ser exploradas de diferentes formas e sob inúmeros ângulos. Em nosso trabalho, a análise de conteúdo utilizou temas recorrentes no discurso dos alunos, que deram origem a determinadas categorias.

O processo de análise de dados do trabalho seguiu padronização utilizada em análise qualitativa ${ }^{19,25,26}$, sintetizada no diagrama a seguir:
A) Leitura dos diários de campo
B) Coleta de dados
C) Categorias (reincidência e relevância)
D) Revisão de categorias
E) Seleção de exemplos de âncoras
$\downarrow$
F) Interpretação do sistema de categorias

Pela leitura dos diários de campo foram coletados dados por meio da utilização de fichas, como já explicado. Esse material foi revisado de modo a serem estabelecidas categorias - dessa forma, o processo de criação delas foi indutivo. Utilizaram-se dois critérios principais de categorização ${ }^{27}$ : repetição (reincidência das manifestações) e relevância (possibilidade de confirmação ou refutação das hipóteses iniciais da investigação).

Uma vez estabelecidas, as categorias foram revistas e cada uma delas recebeu um nome e um número de código. Todo o material disponível foi relido, e os números referentes às categorias foram atribuídos aos diversos fragmentos. Em seguida, selecionaram-se os chamados exemplos de âncora segmentos de texto específicos relacionados com uma dada categoria e que servem de exemplo para ela ${ }^{26}$. A etapa final consistiu na interpretação do sistema de categorias, em termos das questões da pesquisa e do quadro referencial teórico.

Tendo em vista os objetivos do presente trabalho, foram selecionadas as seguintes categorias:

- Avaliação dos alunos acerca das atividades didáticas;

- Julgamentos e reações emocionais relacionados ao professor; 
- Utilização do professor como modelo;

- Auto-avaliação do aluno;

- Reações emocionais despertadas no contato com o paciente;

- Manifestações de empatia.

\section{RESULTADOS}

\section{Avaliação dos alunos acerca das atividades didáticas}

Boa parte dos diários de campo se refere ao relato das diversas atividades em que os alunos estão envolvidos em suas aulas práticas. Eles costumam estabelecer julgamentos de valor acerca delas. Sobre discussão de caso clínico de aparelho respiratório: "Foi muito bom, visto que as professoras explicaram os termos desconhecidos, tiraram as dúvidas e fizeram com que os alunos participassem."

Falar das atividades pode ser uma oportunidade para o estudante dar sugestões sobre elas: "Foi ótimo! Acho que temos que fazer essas atividades em todas as aulas."

Certos alunos mostram compreensão acerca dos princípios pedagógicos adotados. Sobre o processo de aprender a fazer anamnese por meio da leitura delas e da posterior correção de falhas, diz um aluno que é "muito mais eficiente do que apenas mostrar a maneira correta".

Por vezes, existe uma grande aceitação da abordagem pedagógica. No início do semestre, uma aluna refere a descoberta de um "novo mundo", "dentro de um sistema acadêmico que, até então, para nós, parecia comida enlatada, vinha empacotada e pronta, só tínhamos que engolir!!!"

Nem sempre, porém, o estudante aprova o que acontece. Estimula-se, por exemplo, a busca ativa de conhecimento por parte do aprendiz. Um aluno considerou negativo perceber que "todo o processo teórico médico pode ser aprendido de forma autodidata".

Aprender o exame físico praticando inicialmente entre eles costuma ser bem aceito. "Mais uma vez destaco a importância de treinarmos tudo o que aprendemos dentro do grupo: isso nos dá segurança de nos portarmos diante do paciente."

Há uma boa aceitação para trabalhar em turmas pequenas conduzidas pelo mesmo docente, o que é bem compreendido pelo seguinte aluno: "A grande vantagem que achei da subdivisão em pequenos grupos é que pude me sentir mais à vontade para expor minhas dúvidas e que o professor pode dar muito mais atenção aos alunos. Além disto, a relação interpessoal fica muito mais fortalecida, tanto professoraluno, quanto aluno-professor."

\section{Julgamentos e reações emocionais relacionados ao professor}

A atuação do professor é continuamente avaliada. Os estudantes se mostram atentos ao desempenho didático do professor: "tenho a impressão de que não prepara as aulas, vai explicando o que vai lembrando." Também valorizam aspectos relacionais: "a todo tempo parecia que ela era nossa amiga de anos e que conversaríamos sobre nossas vidas, sentimentos".

A proximidade com os professores, aspecto típico da disciplina, costuma ser bastante valorizada pelos alunos da disciplina: "um dos melhores aspectos da propedêutica é a aproximação com os professores". Entende-se que essa situação é fator estimulante para o aprendizado: "essa relação de amizade entre professor e aluno é muito importante para o bom desenvolvimento do trabalho". No entanto, isso às vezes desperta certa estranheza: "na faculdade não encontrei muitos professores gentis".

O processo de escrever livremente, com a garantia de sigilo, permite ao aluno expressar, de forma sincera, reações emocionais nos professores. Não é incomum o desenvolvimento de fortes sentimentos em relação aos professores: "eu amo a professora, acho ela uma pessoa maravilhosa."

Professores muito exigentes em relação ao desempenho do aluno podem despertar uma reação negativa. Sobre determinado professor, comentam os estudantes: "sinto-me muito pressionada por ele já que o mesmo não consegue entender nossas limitações e dúvidas"; "parece que nunca é suficiente, pois ele nunca está satisfeito"

A motivação para aprender pode ser bastante influenciada pelo docente. Uma estudante se diz muito decepcionada com a disciplina: "a professora não nos entusiasma a estudar, a procurar os pacientes".

\section{Utilização do professor como modelo}

Outro aspecto observado é que, quando é admirado e estimado, o docente funciona como um modelo para o aluno. O mestre pode ser tomado como um exemplo profissional pelo estudante: "Fiquei encantado pelo jeito como a professora abordou os pacientes, muito carinhosa e meiga, como se já a conhecesse há décadas. Ela deve ser uma excelente médica e sempre é bom termos professores nos quais podemos nos espelhar."

A influência também pode ser verificada pela opção pela especialidade do mestre: "se eu me tornar cardiologista, parte da culpa é deste professor".

Por vezes, a interação com o docente traz conseqüências mais profundas, em nível pessoal. Certo aluno foi muito ajudado pela professora em relação a certas dificuldades de ordem pessoal e termina o diário ressaltando a importância dela em suas mudanças nesse processo. "Essa matéria não vai servir só para a minha formação médica, mas também para minha vida."

\section{Auto-avaliação do aluno}

O diário de campo também oferece uma oportunidade ao aluno de continuamente se auto-avaliar em termos de seu 
aprendizado, assim como em relação a certas atitudes e comportamentos que assume. Comentando acerca da avaliação formativa a que fora submetida, uma aluna se refere ao exame físico: "me esqueci de muitas coisas e algumas coisas que eu sabia eu fiz errado". Outro aluno, com dificuldades de acompanhar o curso por se dedicar a outra atividade paralela, diz: "estou muito decepcionado com a faculdade, comigo pela minha falta de interesse no estudo e meu desconforto nas anamneses com o paciente".

Dessa forma, com base no diário de campo se pode fazer um acompanhamento bastante sensível de como vai se processando o processo de aprendizado do aluno. Suas dúvidas, suas incertezas, a construção progressiva de uma segurança maior, tudo isso é visto claramente no acompanhamento seqüencial dos relatos do estudante ao longo do semestre.

\section{Reações emocionais despertadas no contato com o paciente}

Sem dúvida, um dos aspectos mais ricos da leitura dos diários de campo se refere à observação de como se processam os primeiros contatos com os pacientes. Na disciplina, o aluno, em geral, pela primeira vez se vê frente a frente com doentes.

A primeira anamnese costuma despertar significativas reações emocionais nos estudantes. "Sensação de angústia, medo e euforia se misturavam [...]" "Hoje foi um dia crucial na minha formação e na minha vida: fiz a minha primeira anamnese."

A realização dos exames físicos iniciais costuma provocar ansiedade nos alunos: "viemos armados de estetoscópio e tensiômetro para iniciarmos uma guerra contra nossos medos e receios relacionados ao exame físico."

O contato com os doentes sem ter recursos para ajudá-los provoca sentimentos marcantes de impotência. "O mais triste de ser médico deve ser ter que conviver com este lado ruim da profissão. Observar o sofrimento e não poder fazer nada."

$\mathrm{O}$ fato de os doentes serem utilizados como objeto de estudo incomoda grande número de alunos: "sempre tenho a sensação de estar expondo a pessoa a uma situação muito ruim." No entanto, uma parte deles compreende que, mesmo sem terem muito a oferecer, trazem uma outra contribuição ao doente: "com uma simples conversa já estamos fazendo um bem enorme aos pacientes."

Os alunos torcem pela melhora dos doentes, e é difícil aceitar prognósticos sombrios: "Eu sempre penso que o paciente vai se recuperar. Me decepciono toda vez que descubro que isto não vai acontecer."

O contato com a morte, muitas vezes, tem significativo impacto nos estudantes. Uma aluna comentou bastante sobre ter assistido um paciente de 16 anos, que ela conhecia, morrer, e reflete: "como as pessoas são tão frágeis, uma hora estão vivos e falando com você [...] e na outra morrem".

\section{Manifestações de empatia}

O contato com outros seres humanos que enfrentam situações de dor e sofrimento põe em foco a questão da empatia, o que é descrito por uma aluna: "ser médico é muito mais que ajudar pessoas, é colocar-se em todos os momentos no lugar do paciente".

O modelo do professor é importante no desenvolvimento da empatia por parte do aluno: "Ela nos mostrou o verdadeiro valor desta nossa profissão, que é o de poder construir uma relação com uma pessoa que está em um dos momentos mais delicados de sua vida, quando sua saúde está em questão."

O fato de o estudante ser colocado, como parte do treinamento, como "paciente" também favorece o processo empático: "É surpreendente tomar consciência de quão incômoda é essa situação, o que nos estimula cada vez mais a ter paciência, delicadeza e cuidado ao lidar com as pessoas."

Certos estudantes revelam uma atitude humana diante dos indivíduos doentes com que se deparam ao longo do semestre. Um aluno destaca a importância de, além dos conhecimentos médicos, tratar "com bastante carinho e atenção os pacientes que nos ajudarão nesta jornada".

Outros alunos, entretanto, enfocam o paciente de forma fria, como meros objetos de estudo: "O que chamou a atenção durante o exame foi o olhar dos alunos sobre o paciente como um objeto de estudo, uma fonte do conhecimento [...]"

O fato de se colocar no lugar da outra pessoa traz, por vezes, incômodo para o aluno: "Acho que não me sinto bem porque eu não gostaria que fizessem isso comigo, eu me sinto uma agressora, que não sabe respeitar a privacidade do outro."

Essa sensibilidade frente aos doentes pode, às vezes, repercutir intensamente nos estudantes: "Acho que acabo me envolvendo muito com os problemas dos pacientes". Com o correr do tempo, entretanto, pode acontecer uma adaptação melhor ao convívio com o sofrimento: "Já estou me acostumando mais com a idéia de ver os pacientes doentes".

\section{DISCUSSÃO}

A experiência na disciplina Clínica Propedêutica Médica I mostra que os diários de campos dos estudantes constituem uma referência significativa acerca do desenvolvimento das atividades didáticas nas aulas práticas e do desempenho dos professores. Alunos têm uma grande vantagem em estabelecer julgamentos sobre o que acontece em salas de aula porque já tiveram a experiência de diversos ambientes de apren- 
dizagem e dispõem de bastante tempo em aula para formar impressões acuradas ${ }^{12}$.

Com base nos diários de campo, pode-se observar como é comum o estabelecimento de relações afetivas intensas com os docentes e a influência que estas têm sobre o aprendizado e a motivação dos alunos. Esses aspectos também se observaram em estudo realizado com alunos de Semiologia, no curso médico ${ }^{15}$. Verificou-se a presença de fortes laços relacionais com o professor. Sendo eles positivos, funcionam como fonte importante de motivação para que os estudantes estudem e se empenhem em desenvolver habilidades frente ao paciente. A existência de conflitos nas relações pode originar depressão e desestímulo não só para estudar, como para empreender um bom relacionamento com os pacientes.

Se não há um clima de atenção, cuidado e cordialidade em relação aos estudantes, e os próprios professores não zelaram bem por si mesmos, não se consegue uma atmosfera ideal de cuidado para os pacientes. Tratamento áspero concedido aos que precisam se desvelar pelos outros não consegue coexistir com apoio e calor humano para com os clientes ${ }^{28}$. $\mathrm{O}$ docente da escola médica, assim, precisa dar conta de que sua relação com o aluno é tão importante quanto a sua interação com o paciente. O estudante, por outro lado, só desenvolverá a percepção do doente como pessoa se ele mesmo for visto e considerado dessa forma ${ }^{29}$. Além disso, o modelo de relação professor-aluno tem significativa influência na formação da identidade dos futuros médicos ${ }^{14}$.

Desse modo, um contínuo acompanhamento do relacionamento docente-discente reveste-se de especial importância no curso de Medicina, em particular numa disciplina em que o estudante começa a construir seu papel de médico. O diário de campo funciona como um instrumento especialmente sensível de avaliação dessa relação. Além disso, uma vez que, por meio dele, o aluno pode compartilhar suas experiências e ser percebido em sua individualidade, o diário favorece que veja o paciente como pessoa e não como caso clínico.

A observação de que o professor de turma, em Clínica Propedêutica Médica I é tomado como modelo encontra apoio numa das teorias psicológicas acerca do processo de aprendizado, a chamada aprendizagem por observação. Assim, uma pessoa tende a reproduzir as ações, atitudes e respostas emocionais que apresentam os modelos da vida real ou simbóli$\mathrm{ca}^{30}$. Uma das formas de aprendizagem acontece quando o estudante quer imitar um modelo admirado ou de status elevado $^{31}$, como pode ser o caso do professor.

Escrever o diário de campo estimula o aluno a se autoavaliar e registrar a evolução de sua aprendizagem. O processo de auto-avaliação constitui um meio significativo de o indi- víduo assumir a responsabilidade por seu aprendizado ${ }^{32}$, tornando-se o estudante um elemento mais ativo no processo de aprendizagem. Por outro lado, a auto-avaliação tem uma função pedagógica, pois se inteirar dos próprios erros e acertos constitui a melhor forma de se aperfeiçoar ${ }^{33}$. Sabe-se, também, que a percepção dos acertos é elemento fundamental na constituição da identidade profissional ${ }^{34}$.

Pela leitura dos diários de campo, observa-se que os primeiros contatos com pacientes se fazem acompanhar por diversas angústias entre os estudantes. Dados de literatura confirmam esses achados ${ }^{35}$. Assim, existe o incômodo trazido pela situação de ter de aprender em seus semelhantes, o que gera sentimentos de ser invasivo ou estar abusando do paciente. Deparar-se com a morte traz o sofrimento de saber que nem sempre se pode evitá-la. Lidar com doentes terminais ou crônicos desperta sentimentos de impotência nos alunos, o que é agravado pelo fato de assumirem uma falsa posição de doutor, estando cientes de que não sabem realmente o que fazer diante das situações.

Lidar com a morte tem sido assinalado como uma dificuldade comum entre estudantes de Medicina e profissionais da área $34,36,37,38,39$. A leitura dos diários de campo nos indica como nossos alunos se mostram mobilizados pela questão, embora alguns deles se refugiem numa aparente atitude de indiferença, tentando ignorar a situação.

Do ponto de vista psicológico, como vivencia situações emocionalmente significativas, é importante haver condições para que o aluno de Medicina possa ser ouvido e compreendido, e possa compartilhar seus sentimentos acerca de si mesmo e em relação ao doente. Caso isso não aconteça, sua experiência emocional não conseguirá ser adequadamente assimilada por sua mente, havendo o risco de surgirem mecanismos defensivos do ego, tais como negação, dissociação e intelectualização, levando a uma alienação dos aspectos humanos da profissão. No entanto, existe o receio de que, ao expor tais sentimentos a professores e colegas, venha a ser criticado ou considerado fraco ${ }^{34,35}$. Sabe-se, inclusive, que há uma tendência maior, nos primeiros anos, a que ele se identifique mais com os pacientes que com os médicos ${ }^{35}$. $\mathrm{O}$ estímulo à manifestação desses aspectos nos diários de campo, dirigidos a uma pessoa que não conduz turmas práticas e que assume uma atitude de atenção e acolhimento diante do que é escrito, favorece que isso aconteça num clima de abertura e confiança. Por outro lado, as experiências emocionalmente significativas ao longo da educação médica podem provocar reflexão sobre a ação e desenvolvimento consciente da identidade profissional ${ }^{41}$.

Sabe-se que a empatia é o principal componente de uma relação médico-paciente satisfatória, de tal modo que cultivá- 
la representa um objetivo de ensino proposto pela Association of American Medical Colleges (AAMC) para todas as escolas de Medicina americanas. Diversos estudos têm demonstrado a possibilidade de adotar, de forma bem-sucedida, diferentes estratégias para desenvolver a empatia em alunos de Medicina ${ }^{42-45}$. Vamos destacar um deles, por seu significado para o nosso trabalho. Estudantes de Medicina do segundo ano foram estimulados a escrever experiências pessoais com a doença e a testemunhar também as histórias de seus colegas. O exercício foi bem recebido pelos alunos e altamente recomendado por eles para outros estudantes e residentes. $\mathrm{O}$ exercício escrito reflexivo pode ser incorporado no currículo médico com o fim de aumentar a empatia dos treinandos, concluem os autores ${ }^{46}$.

O processo de escrever os diários de campo, nos quais o aluno relata seus contatos com os pacientes e as reações emocionais por eles despertadas, pode, desse modo, ser encarado como uma forma de incrementar a empatia do estudante. Nos Estados Unidos, inclusive, há referência de que muitas escolas médicas e programas de residência têm solicitado dos treinandos que escrevam sobre suas experiências clínicas em diários, relatos sobre circunstâncias difíceis, e o que se chama de "prontuários paralelos", em que anotam os diversos sentimentos despertados ao lidarem com os doentes ${ }^{47}$.

Em sua prática, o aluno, muitas vezes, pensa sobre o que faz ao mesmo tempo em que atua, ou seja, há uma "reflexãona-ação". Ao escrever o diário de campo, ocorre um distanciamento da ação, e surge a possibilidade de refletir novamente sobre eventos passados, de modo que ocorre a chamada "reflexão sobre a reflexão-na-ação". Este é um dos elementos centrais no desenvolvimento de uma aprendizagem reflexiva e favorece uma nova compreensão acerca dos problemas, assim como possibilita modificações em ações futuras ${ }^{48}$. Desse modo, diários reflexivos têm sido reconhecidos na literatura como uma forma de facilitar a aprendizagem reflexiva. Cumpre assinalar que desenvolver educandos capazes de reflexão tem se tornado elemento central em muitos programas de educação profissional, inclusive na área médica ${ }^{49}$.

Na literatura especializada, descrevem-se as diversas funções da avaliação ${ }^{50-54}$. A seguir, enfocaremos os diários de campo seguindo esse referencial.

Os dados obtidos nos diários de campo são sintetizados e analisados em relatórios periódicos dirigidos à coordenação da disciplina, que dispõe, assim, de contínuas informações acerca do andamento das atividades práticas. Em certas situações, percebe-se a necessidade de se introduzirem modificações, para obter melhores resultados em termos dos objetivos educacionais estabelecidos. Tais mudanças são discutidas com o corpo docente. Com o feedback trazido pelos relatos dos alunos, pode-se de corrigir a tempo eventuais deficiências. Dessa forma, o diário de campo preenche uma das funções atribuídas ao processo de avaliação, que é a de retroinformação.

Tem o diário de campo uma outra função de avaliação, a de controle: verificar os resultados obtidos no desenvolvimento das atividades didáticas, identificando pontos fortes e fracos do processo de ensino-aprendizagem, averiguando se os objetivos educacionais estão sendo atingidos e informando acerca do progresso na aprendizagem em dada unidade de ensino. Por outro lado, vem sendo utilizado na disciplina como uma das formas de avaliação do desempenho do aluno em termos afetivos (interesses, atitudes e valores), ou seja, com função de classificação.

Sendo utilizado como uma forma de auto-avaliação do discente, o diário de campo preenche mais uma função de avaliação, que se relaciona principalmente com o processo de se auto-avaliar: desenvolvimento individual, facilitando o autoconhecimento do aluno. Além disso, o acompanhamento dos diários de campo permite identificar alunos ou grupos de alunos que necessitam de atenção mais individualizada, seja por dificuldades em termos de aprendizado ou por situações de ordem pessoal, configurando-se mais uma função de avaliação, a de diagnóstico.

Uma vez que o diário de campo exerce as funções de retroalimentação, controle, classificação, desenvolvimento individual e diagnóstico, preenche, assim, todos os aspectos relacionados à utilização de um instrumento de avaliação e como tal pode ser considerado. Por enfocar processos e aspectos subjetivos, ao invés de se fundamentar em quantificações das observações, utiliza uma abordagem qualitativa da avaliação. Em tese de doutorado em Educação, Peixinho ${ }^{55}$ faz referências às diversas funções de avaliação exercidas pelo diário de campo no mesmo contexto do nosso trabalho.

Tendo o presente trabalho o formato de estudo de caso, é passível de uma crítica freqüente a esse tipo de desenho metodológico - a de que não permite a generalização de resultados. Como se refere a uma situação particular - diários de campo de alunos de Medicina de determinada disciplina -, não nos informa acerca das semelhanças e diferenças com outros casos, nem sobre a freqüência de um ou outro aspecto $^{24}$.

Em estudos quantitativos, essa possibilidade de generalização de resultados se relaciona com a chamada validade externa. Em termos da pesquisa qualitativa, podemos aceitar como equivalente de tal conceito a transferabilidade ${ }^{56}$. Esta não se refere à possibilidade de reproduzir os achados nas mesmas condições em outros estudos, mas, sim, àquela de 
utilizar procedimentos e resultados encontrados em situações semelhantes, levando em conta as peculiaridades dos novos $\operatorname{conceitos}^{57}$. Ou seja, observando-se as evidências apresentadas e a interpretação dada a elas, pode-se verificar se as conclusões obtidas se mostram aplicáveis a outras situações. Acredita-se que a responsabilidade de definir se certos aspectos são passíveis ou não de aplicação a outros casos fica por conta dos leitores, que avaliam se há realmente uma contribuição relevante, podendo ser útil de alguma forma em sua própria situação ${ }^{58}$.

Nos estudos qualitativos, adotam-se como critérios de qualidade conceitos correspondentes aos empregados pela pesquisa quantitativa, conforme a sistematização desenvolvida por Lincoln e Guba ${ }^{56}$, assim como há procedimentos aceitos para testar tais critérios ${ }^{59}$. Na elaboração do nosso trabalho, procuramos levá-los em conta.

$\mathrm{Na}$ medida em que o diário de campo, conforme aqui enfocado, exerce as funções de avaliação, seu emprego poderia ser testado em outras disciplinas do curso médico que envolvam contato direto com pacientes ou mesmo em outras áreas da saúde, desde que se façam as necessárias adaptações. Por outro lado, a riqueza de achados proporcionados pelo relato livre dos estudantes de Medicina acerca de suas primeiras experiências com os doentes, sua relação com professores e sobre como vão construindo o papel de médico oferece dados significativos àqueles que se dedicam a estudar tais aspectos. Além disso, tais informações são úteis para educadores médicos, pois trazem a perspectiva do estudante acerca de como vivencia diferentes métodos pedagógicos e de como se processa seu aprendizado.

Seguindo os primeiros passos empreendidos pelo nosso estudo, é possível refinar o diário de campo no exercício de suas diversas funções de avaliação, particularmente no seu aspecto classificatório. Considerando o efeito positivo de escrever sobre experiências emocionais relacionadas com a prática médica, outra forma de pesquisa seria estabelecer que efeitos isso produz realmente no desempenho dos estudantes.

Em projeto de pesquisa em andamento na disciplina Clínica Propedêutica Médica I, procuraremos verificar, por meio dos diários de campo, como se refletem na prática de alunos conteúdos discutidos em pequenos grupos, cujo principal objetivo é trabalhar a relação médico-paciente.

Por fim, o emprego dos diários de campo oferece a oportunidade de explorar com maior profundidade certos aspectos como a relação professor-aluno, o desenvolvimento da identidade médica e o processo empático frente aos pacientes.

\section{CONCLUSÕES}

A experiência com o diário de campo na disciplina Clínica Propedêutica Médica I, na Faculdade de Medicina da Universidade Federal da Bahia, mostra que ele pode oferecer um vasto leque de aplicações, tais como:

- Permite acompanhar as atividades práticas e a atuação didática dos professores, utilizando a perspectiva dos próprios estudantes;

- Traz conhecimento acerca de aspectos envolvidos na relação professor-aluno;

- Fornece subsídios para a avaliação dos estudantes em termos afetivos;

- Serve como recurso para a reformulação da prática pedagógica a partir do feedback dos alunos;

- Funciona para o estudante como instrumento de autoavaliação (registro da evolução do aprendizado);

- Facilita a comunicação entre os alunos e a coordenação da disciplina;

- Auxilia na elaboração de experiências emocionalmente significativas dos estudantes nos primeiros contatos com pacientes.

Dessa forma, configura-se o diário de campo como um instrumento de significativo valor, não só considerando as diversas funções que desempenha em termos de avaliação educacional, como também como meio de favorecer a aprendizagem reflexiva do aluno. Além disso, contribui para o desenvolvimento da empatia e da competência narrativa, por meio das conseqüências advindas do processo de escrever suas diversas experiências.

Acredita-se, portanto, que, além de apresentar inegável utilidade no campo da educação médica, oferece também material bastante rico acerca da perspectiva dos estudantes sobre o processo de ensino-aprendizagem nessa área do conhecimento.

\section{REFERÊNCIAS}

1. Delors J. Quatro pilares da educação. Relatório da Unesco. Disponível em: <hhtp//infoutil.org/4pilares/text-cont./ delors-pilares.htm $>$. [Acesso em: 28 de junho de 2003].

2. Perez EP. A propósito da educação médica. Rev Bras Saúde Matern Infant 2004; 4(1): 9-13.

3. World Federation for Medical Education. The Edinburgh Declaration. The Lancet 1988; 2: p. 464.

4. Briani MC. História e construção social do currículo na educação médica: a trajetória do curso de medicina da fa- 
culdade de ciências médicas da Unicamp. [Dissertação]. Campinas, SP : UNICAMP, 2003.

5. Chaves MM. Educação médica: uma mudança de paradigma. Boletim ABEM 2000; 28(4): 10-11.

6. Tyler RW. Princípios básicos de currículo e ensino. 3 ed. Porto Alegre (RS): Globo; 1976.

7. Bloom BS, Engelhart MD, Furstin EJ, Hill WH, Krathwolhl. Taxionomia de objetivos educacionais. 5 ed. Porto Alegre (RS): Globo; 1976.

8. Troncon LEA. Avaliação do estudante de medicina. Medicina. 1996; 29(4): 429-39.

9. Melchior MC. Avaliação pedagógica: função e necessidade. 2 ed. Porto Alegre (RS): Mercado Aberto; 1999.

10. Campos DMS. Psicologia da aprendizagem. 17 ed. Petrópolis (RJ): Vozes; 1985.

11. Vianna HM. Introdução à avaliação educacional. São Paulo: IBRASA; 1989.

12. Brown T. Student perspectives on effective and ineffective learning: experiences in a Physics Class, 1999. Disponível em: http:/ / scied.gsu.edu/Hassard/phd/brownc-3.html. [Acesso em : 13 de junho de 2004].

13. Rogers CR. Psicoterapia e consulta psicológica. São Paulo: Martins Fontes; 1987.

14. Ramos-Cerqueira ATAR,Lima MCP. A formação da identidade do médico: implicações para o ensino de graduação em Medicina. Interface - Comunicação, Saúde Educação. 2002; 6: p. 107-16.

15. Sayd JD, Silva DA, Ribeiro MPD. O aprendizado de semiologia em um currículo tradicional. Rev Bras Educ Med 2003; 27(2):104-113.

16. Machado AR. O Diário de leituras: a introdução de um novo instrumento na escola. São Paulo: Martins Fontes; 1998.

17. Charon R. Narrative and medicine. N Engl J Med 2004; 350(9): p. 862-4.

18. Strauss A, Corbin J. Basics of qualitative research: grounded theory procedures and techniques. London: Sage Publications; 1990.

19. Bogdan R, Biklen S. Investigação qualitativa em educação. Porto: Editora Porto; 1994.

20. Lüdke M, André MEDA. Pesquisa em educação: abordagens qualitativas. São Paulo: EPU; 1986.

21. Hancock B. An introduction to qualitative research. Trent Focus Group, 2002. [Consultado em: 05 de abril de 2004]. Disponível em: http:/ / www.trent.focus.org.uk.
22. Bensabat I, Goldstein DK, Mead M. The case research strategy in studies of information systems. MIS Quartely 1987; 11(3): p. 369-386.

23. Tellis W. Introduction to case study. The Qualitative Report 1997; 3(2). Disponível em: http:/ / www.nova.edu/ssss / QR/QR3-3/tellis2.html [Acesso em: 18 de maio de 2004].

24. Ponte JP. O estudo de caso na investigação em educação matemática. Quadrante 1994; 3(1): 3-18.

25. Mayring P. Qualitative content analysis. Forum: Qualitative Social Research [On-line Journal] 2000; 1(2). Disponível em: <http:/ / qualitative-research.net/fqs-e/2-00inhalt-e.htm.> [Acesso em: 01 de agosto de 2004].

26. Mayring P. Introdução à pesquisa social qualitativa. Weinheim: Beltz; 2002. Disponível em : <http:// www.unb.br/ip/IPA/pdf/Mayring043.pdf> [Acesso em: 01 de agosto de 2004].

27. Turato ER. Tratado da metodologia de pesquisa clínicoqualitativa: construção teórico-epistemológica, discussão comparada e aplicação nas áreas de saúde e humanas. Petrópolis (RJ): Vozes; 2003.

28. Branch Jr WT. Supporting the moral development of medical students. Acad Med 2000; 75(7): 748-9.

29. Cruz EMTN. Formando médicos da pessoa - o resgate das relações médico-paciente e o professor-aluno. Rev Bras Educ Méd 1997; 21(2/3): 23-29.

30. Bandura A, Walters RH. Aprendizaje social y desarrollo de la personalidad. Madri: Alianza Editorial; 1974.

31. Woolfolk A. Psicologia da educação. 7 ed. Porto Alegre (RS): Artes Médicas; 2000.

32. Rogers C. Liberdade para aprender. 4 ed. Belo Horizonte: Interlivros; 1972.

33. Haydt RCC. Avaliação do processo ensino-aprendizagem. 6 ed. São Paulo: Ática; 1997.

34. Martins MCFN. Cuidando do futuro cuidador. In: Marco, MA, editor. A face humana da medicina: do modelo biomédico ao modelo biopsicossocial. São Paulo: Casa do Psicólogo; 2003.

35. Silva JFRS. A formação do médico. In: Marco, MA, editor. A face humana da medicina. São Paulo: Casa do Psicólogo; 2003.

36. Sayd JD. A escola médica e seus implícitos sobre a morte. Rev Bras Educ Méd 1993; 17(3): p. 14-20.

37. Vianna A, Picelli H. O estudante, o médico e o professor de medicina perante a morte e o paciente terminal. Rev Assoc Med Bras 1998; 44(11): 21-27. 
38. Rosa CAP. A morte e o ensino médico. Rev Bras Educ Méd 1999; 23(2/3): p. 52-67.

39. Nogueira-Martins LA. Saúde mental dos profissionais de saúde. Rev Bras Med Trab 2003; 1(1): p. 59-71.

40. Castro FC. Os temores na formação e na prática da medicina: aspectos psicológicos. Rev Bras Educ Med 2004; 28(1): 38-45.

41. Ryynänen K. Constructing physician's professional identity - exploration of student's critical experiences in medical education. [Dissertation]. Finland: University of Oulu, Faculty of Medicine; 2001.

42. Fine VK, Therrien ME. Empathy in the doctor-patient relationship: skill training for medical students. J Med Educ 1977; 52(9): 752-7.

43. Poole AD, Sanson-Fisher RW. Long-term effects of empathy training on the interview skills of medical students. Patient Couns Health Educ 1980; 2(3): 125-127.

44. Ikemi A, Masui T. An experiential learning course on teaching humanistic skills to medical students - effect on empathy and regard for others. J UOEH 1984; 6(3): 265-71.

45. Shapiro J, Boker J. Teaching empathy to first year medical students: evaluation of an elective literature and medicine course. Educ Health 2004; 1(1): p. 73-84.

46. DasGupta S, Charon R. Personal illness narratives: using reflective writing to teach empathy. Acad Med 2004; 79(4): 351-6.

47. Charon R. Narrative medicine: form, function, and ethics. Ann Intern Med 2001; 134(1): p. 83-87.

48. Gomes JB, Casagrande LD. A educação reflexiva na pósmodernidade: uma revisão bibliográfica. Rev. Latino-Am. Enfermagem 2005; 10(5): 696-703.

49. Tang C. Reflective diaries as a means of facilitating and assessing reflection. 2002. Disponível em: <http://www.ecu.edu.au/ conferences / herdsa / main / papers / nonref / pdf / catherinetang.pdf [Acesso em: 18 de março de 2006].

50. Diniz T. Sistema de avaliação em aprendizagem. Rio de Janeiro: LTC; 1982.

51. Lima AO. Avaliação escolar: julgamento ou construção? 5 ed. Petrópolis (RJ): Vozes; 1994.
52. Sant'Anna IM. Por que avaliar? Como avaliar: critérios e instrumentos. 2 ed. Petrópolis (RJ): Vozes; 1995.

53. Souza SZL. Revisando a teoria da avaliação da aprendizagem. In: Sousa CP (org.) Avaliação do rendimento escolar. 6 ed. Campinas (SP): Papirus; 1997.

54. Turra CMG, Enricone D, Sant'Anna FM, André LC. Planejamento de ensino e avaliação. 11 ed. Porto Alegre (RS): Sagra Luzzato; 1998.

55. Peixinho AL. Educação médica: o desafio de sua transformação. [Tese]. Salvador (BA): Universidade Federal da Bahia, Faculdade de Educação; 2001.

56. Lincoln YS, Guba EG. Naturalistic inquiry. Thousand Oaks, CA: Sage; 1985.

57. Silva RC. A falsa dicotomia qualitative-quantitativo: paradigmas que informam nossas práticas de pesquisa. In: Romanelli G, Biasolli-Alves ZMN. Diálogos metodológicos sobre prática da pesquisa. Ribeirão Preto (SP): Legis-Suma; 1998.

58. Hoepfl MC. Choosing qualitative research: a primer for technology education researchers. Journal of Technology Education. 1997; 9(1): p. 12-39.

59. Anfara Jr VA, Brown KM, Mangione TL. Qualitative analysis on stage: making the research process more public. Educational Researcher. 2002; 31(7): p. 28-38.

\section{Conflito de Interesses}

De acordo com a Resolução CEM-1595/2000 em 18/05/2000, que trata de conflito de interesses, declaramos que a pesquisa relacionada com nosso artigo "Avaliação Qualitativa em Medicina: Experiência em Propedêutica na UFBA, 2003", apresentado à Revista Brasileira de Educação Médica para publicação, foi realizada com recursos financeiros próprios, assim como não houve nenhum tipo de interesse pessoal, profissional ou político na realização do trabalho.

\section{Endereço para correspondência}

Dolores Araújo

Rua Com. Horácio Urpia, 1 - apto. 1001 - Graça

40150-250 - Salvador - BA

E-mail: doloresaraujo@terra.com.br 